\title{
Characterization and utilization of acid tar waste from crude benzol processing for environmental sustainability
}

\author{
C. Danha ${ }^{1}$, C. H. Chihobo ${ }^{2}$, D. Musademba ${ }^{2}$, D. J. Simbi, P. K. Kuipa \& \\ E. Jonathan \\ ${ }^{I}$ Environmental science, Chinhoyi University of Technology, Zimbabwe \\ ${ }^{2}$ Fuel and energy, Chinhoyi University of Technology, Zimbabwe
}

\begin{abstract}
This paper reviews the utilization of acid tars with the overall aim of reducing or eradicating the environmental problems associated with acid tar landfill disposal at a local crude benzol refinery in Zimbabwe .The review focused on disposal, characterization, composition and utilization of acid tars. Peer reviewed journal and conference papers from 1980 to the current year were considered. The papers reviewed were mainly from petroleum processing since the acidic nature of the tar can be assumed to be similar to that of crude benzol processing and the databases used were Science direct, Hinari and Agora. The effects of the disposal of acid tar in lagoon were reviewed. The utilisation of acid tar waste is dependent on the chemical composition hence work on the characterization of acid tars was reviewed. The use G.C-MS was common in the characterization of acid tars as compared to other analytical techniques. Some of the utilization processes which were reviewed included among others the conversion of acid tar to asphaltenes, production of pavement binders, energy utilisation, acid tar co-processing, membrane technology, ion exchangers and carbon adsorbents technique. The utilization of acid tar waste hinges on effective treatment methods owing to its complex chemical composition.
\end{abstract}

Keywords: Crude benzol, Acid tar, Refining, Lagoons, Characterisation, Asphaltenes, Energy, membrane technology, Remediation, Disposal

\section{Introduction}

Acid tars are basically derived from three processes namely re-refining of spent lubricating oils, refining of petroleum fractions and in crude benzol refining. The refining of crude benzol involves washing with concentrated sulphuric acid which sulphonates the more undesirable compounds and allows easier separation and recovery of the Benzene, Toluene and Xylene fractions. The Acidic tarry waste material generated is regarded industrially as a product of low commercial value and is disposed off in lagoons; however, acid tars from crude benzol can be feedstocks for the synthesis of other valuable products. The focus in European, American and Asian countries is on the remediation of acid tar lagoons created by former gas works sites, benzol refining, refining petroleum fractions and in oil re-refining. The remediation activities were mainly centred on reclaiming the land, burning and utilisation of the acid tars. In Africa and Zimbabwe in particular there is no literature in support of the remediation and utilisation of the acid tars. The main objective of this literature review was to make a close analysis of the various technical and scientific ways of utilising acid tars.

\section{Environmental effects of acid tar disposal}

Disposing acid tar in open lagoons expose the environment to different impacts since the effects are dependent on the temperature and moisture content [1]. For example acidification of groundwater and mineral oil was observed with high levels of sulphates in areas close to the Pesniski Dvor dumping site [2]. Environmental risks such as volatiles in the air, dust blow off from exposed and weathered tar surface, leaching to the ground water and surface water are expected from open lagoons [1]. The leaching of the waste affects the ground water and the evolution of gases from the waste also affects the atmosphere which might lead to acid rain which will in turn affect surface water. During storage in holding ponds, the chemical composition of the acid tar changed as a result of leaching of the acid from the tar by rainfall, evolution of sulphur dioxide and condensation of the substances present in the acid tar [3]. [4] Also supports this when he observed the inconsistent chemical composition of the acid tar that changes with time due to the reaction of the organic components with atmospheric oxygen and sulphuric acid. The use of quick lime to neutralise acid tars in lagoons has been found to be environmentally unacceptable since it produces emissions which will lead to environmental problems such as acid rain and global warming [1]. Acid tars contain sulphuric acid thus the effects of sulphuric acid on the environment are the major ones that need to be considered followed by those of organic chemicals such as benzene and other volatile organic compounds. From the literature reviewed, the environmental effects of acid tars disposed in lagoons, have been given little attention. 


\section{Techniques for characterising acid tars}

The proper utilisation of acid tars in any application requires an in depth understanding of the chemical composition of acid tar. The composition of acid tar has been determined using gas chromatography-mass spectrometry (GC-MS) [5], while gas chromatography with a thermal conductivity detector is said to be suitable for analysis of organic compounds [6]. Mass spectrometry detection simplifies the analysis by eliminating the need for standards to identify the organic groups. In another research organic compound content of spent sulphuric acid from benzol refining process was analysed using gas chromatography with flame ionisation detector [7]. The use of Fourier transform infrared (FTIR) spectrometry with gas chromatography-mass spectrometry for characterisation of organics and coal by-products was common [8]; [9]; [5] and [10]. According to [4], FTIR is used to further confirm the presence of organic groups detected by GC-MS. [10], used gas chromatograph and a mass selective detector along side FTIR to determine the organic composition of crude benzene. [8] Used GC-FTIR system were the FT-IR at a frequency range of 4000 to $580 \mathrm{~cm}^{-1}$ at resolution of $8 \mathrm{~cm}^{-1}$ was used as a detector. The role of the GC was to separate the organic components using oven temperatures adapted to each mixture (alkanes, branched alkanes, cycloalkanes and aromatics the temperature range was 28 to $270^{\circ} \mathrm{C}$ ). There are some investigations that just relied on FTIR for characterisation [11]; [12] and [13]. [11] Used FTIR at frequency range of 4000 to $500 \mathrm{~cm}^{-1}$ at a resolution of $4 \mathrm{~cm}^{-1}$ at room temperature.

The use of FTIR for organic acid analysis in aqueous solutions requires $\mathrm{pH}$ monitoring as the spectra vary with $\mathrm{pH}$. The presence of one molar sodium chloride of $\mathrm{pH} 8.5$ ensures that all the organic acids are present in their fully de-protonated form [14]. There is need for pre treatment of the sample so as to avoid co eluting of organic compounds. A sample of coal tar is passed through silica gel and alumina in a column to separate various types of organics using the difference in their ability to adsorb and the difference of polarity between various eluents [15]. Common eluents used are pentane, benzene, ethyl acetate and methanol to end up with aliphatic, aromatics, esters and polar organic compounds [15]. Hexane, benzene and ethanol are solvents which are used to extract different groups of organic compounds from acid tar so that the analysis become easy since different groups differ in their solubility for every solvent [16].

In an investigation for analysis of crude oils and petroleum products, $100 \% \mathrm{n}$-hexane for saturates, $5 \%$ benzene/95\% n-hexane for mono aromatics, $15 \%$ benzene/85\% n-hexane for di-aromatics and $60 \%$ methanol/20\% diethylether $/ 20 \%$ benzene for poly aromatics was used for elution on a silica gel column prior to FTIR [17]. Soxhlet extraction with 1:1 volume of acetone and dichloromethane is used to extract the organics from acid tar [5]. The acid tar is also separated into toluene soluble and insoluble fractions. Toluene soluble is further separated into asphaltene and maltenes using heptanes precipitation [5]. Maltenes are separated into saturates, aromatics and resin through silica gel packed column chromatography using $\mathrm{n}$-hexane, $20 \%(\mathrm{v} / \mathrm{v})$ dichloromethane/ $\mathrm{n}$-hexane and 50\% (v/v) dichloromethane/methanol, solvent is then removed in a fume hood [5]. Due to the complexity of the acid tars various techniques are used as has been shown in the literature available.

IV. Composition and properties of acid tars

The following table summarises the work by various researchers on the composition of acid tars.

Table I: Composition of acid tars

\begin{tabular}{|c|c|c|c|c|c|c|}
\hline \multirow[t]{2}{*}{ Researcher } & \multicolumn{6}{|c|}{ Composition of acid tars (\%) } \\
\hline & Sulphuric acid & Water & Organic oil & resins & $\begin{array}{l}\text { Ash/other } \\
\text { impurities }\end{array}$ & Asphaltene \\
\hline [3] & $45 \pm 5$ & $5.38 \pm 2.63$ & $41.25 \pm 3.75$ & - & 0.076 & - \\
\hline [3] & 12.3 & 28 & 42 & 22 & 5.9 & - \\
\hline [18] & 48.2 & - & 49.5 & - & - & - \\
\hline$[20]$ & - & - & 73 & 24 & - & 3 \\
\hline [16] & 0.014 & 3.21 & 52.15 & 6.29 & 0.14 & 37.85 \\
\hline [7] & 63.8 & - & 6.9 & - & 29.3 & - \\
\hline [5] & - & $9.3 \pm 1.1$ & $32.5 \pm 1.5$ & $0.5 \pm 0.02$ & - & $19.3 \pm 0.6$ \\
\hline [5] & & $7.25 \pm 1$ & $3.1 \pm 0.3$ & $1.8 \pm 0.1$ & & $2.3 \pm 0.2$ \\
\hline
\end{tabular}

Generally the results from Table I indicate that the percentages of organic oils in the acid tars are higher than corresponding sulphuric acid present in the samples. Fresh acid tar has a high percentage of sulphuric acid as compared to the pond acid tar. The composition of acid tar is time dependent. This is also supported by [3] when he observed that the percentage of sulphuric acid decreased with time in storage tanks where a solid film had formed on the surface of the acid tar. [21] Have also shown that there is a decline in sulphuric acid in ponded tars when he observed that the composition of the gas after decomposition of pond acid tar had 28.6 mol \% of 
hydrogen sulphide and less than $1.2 \mathrm{~mol} \%$ of sulphur dioxide. The differences in the percentages of the sulphuric acids may be explained by the fact that the acid is either being consumed by chemical reactions or evaporating into the air, thus there is need to find out what happens to the acid tar the minute it is produced to about a year in a monitored environment. The percentage of sulphuric acid varies from sample to sample. The presence of resins and asphaltenes in ponded acid tars supports that chemical reactions will have taken place over time. The water content is very low in both fresh and pond acid tar.

The character of acid tars is complex. In the characterisation of acid tars, [5] observed two acid groups as evidenced by the two plateaus shown in figure 1, suggesting the presence of both organic acids and inorganic acids in the acid tar.

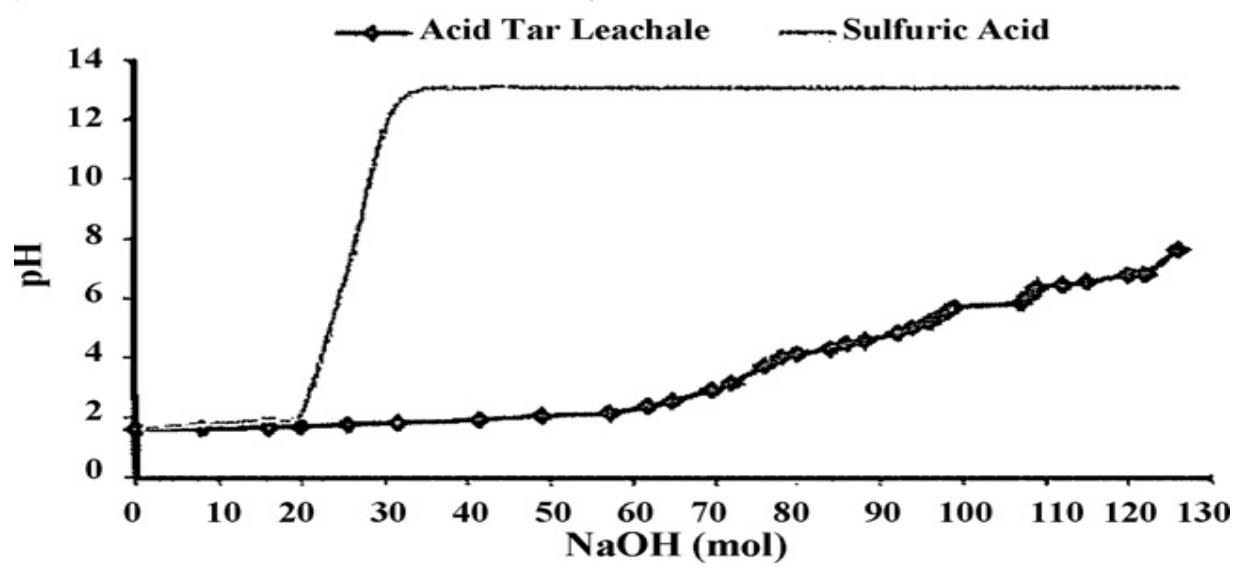

Fig. I: The titration of sodium hydroxide against acid tar [5]

[18] Previously observed that freshly produced acid tars consisted of mainly sulphuric acid, sulphonic acid and carboxylic acid. The $\mathrm{pH}$ of acid tar is variable and depends on the process by which the acid tar is generated, the amount and strength of the sulphuric acid used in the process and pre-treatment prior to disposal [22]. This implies that there is need to determine the composition of acid tar for each set of raw materials used. In studying the Hoole Bank Lagoon in Europe, [19] observed evidence of particles settling at the bottom of the lagoon, and in analysing the acid tars he found that the density of acid tars ranged from 1.2 to $1.4 \mathrm{~g} / \mathrm{ml}$ and the viscosity varied with temperature. In a similar research at the D.I. Mendelev Yaroslav in Russia, [23] observed high ash content of approximately $6.5 \%$ and high viscosity for the bottom layer of acid tars. Ash could be the major part which is being deposited at the bottom.

\section{Utilization and processing of acid tars into asphaltenes}

The processing of fresh acid tar was said to be more difficult than that of acid tar from lagoon due to the high percentages of sulphuric acid [3]. In normal state sulphuric acid mixed with organics does not react with the organic part of the mixture [24]. This then makes the mixture difficult to deal with when fresh and yet once in lagoons reaction with air and water can take place thus reducing the acidity of the mixture. Polymers and inorganic cement techniques were attempted in the 1970s in UK but the processes proved to be more expensive than the neutralisation and landfill dumping of acid tars [22]. Neutralisation is done under controlled temperatures and emissions monitoring since it increases temperature which leads to sulphuric acid and sulphur trioxide evaporating from the mixture if the temperature exceeds $100^{\circ} \mathrm{C}$ [25]. [3] proposed a method for the production of paving asphalt: a three key step process which involved neutralisation of the acid tar with technical calcium oxide at temperatures between 90 and $100^{\circ} \mathrm{C}$; evaporation of water from the reaction mass at 100 to $130^{\circ} \mathrm{C}$ and oxidation of the neutralised mass with air at 160 to $190^{\circ} \mathrm{C}$ in a thermostatic metal reactor with stirrer. In another method by [26] acid tar was converted to asphalt using the thermal cracking method. The resulting product from this method was found to be temperature dependent such that low penetration was observed at high temperatures $\left(460-480^{\circ} \mathrm{C}\right)$ when the product was exposed for 10 minutes. When acid tars are exposed to high temperatures for more than 10 minutes coke formation is prompted instead of asphaltenes and resin which are responsible for the viscosity characteristics of the product. This type of processing requires the control of emissions since the lowest temperatures were 400 to $420^{\circ} \mathrm{C}$ [26]. Thin film cracking of acid tars at $350-400^{\circ} \mathrm{C}$ resulted in asphaltene material of $65-70 \%$, liquid hydrocarbons of $20-25 \%$ and gas of $5-10 \%$ and at $500^{\circ} \mathrm{C}$ coke at $18 \%$ and liquid hydrocarbons $75 \%$ produced [27]. A technology for processing acid tars with the aim of obtaining solid fuel, resins and general use medium oils was proposed by [4]. The proposed technology is based on the use of membrane methods of separation of hydrocarbons and comprises the following steps: heating and filtration to remove acid water and particulate contaminants; neutralisation of the filtered acid tars with an alkali solution; two stage de-asphalting and subsequent series of separation of oil and resin in membrane 
units. The auxiliary stages of the process involved neutralisation and treatment of the acid waters generated and the recovery of the solvents used. Acid tars of the following composition were processed in an experimental set up: acid number, $14 \mathrm{mg} \mathrm{KOH} / \mathrm{g}, 21.7 \%$ paraffin and naphthalene; 5.9\% aromatics; $12.9 \%$ resins; $47.1 \%$ residue (oxidation products, carbenes, carboids, and solid residue) and $12.4 \%$ asphaltenes. The yield from the process was $60 \%$ solid fuel, $12.5 \%$ resin and $26 \%$ oils (industrial type).

\section{Acid tar use in pavement binder production}

Basic properties of bitumen are softening point $\left({ }^{\circ} \mathrm{C}\right)$, penetration $(\mathrm{mm})$ and ductility $(\mathrm{cm})$ [28]. Softening point, penetration, brass breaking point, morphology and rheological properties play a part in the performance of the bitumen [29]. Natural bitumen from Iran consisted of $13 \%$ ash $60 \%$ volatile matter, $28 \%$ fixed carbon and 1-5\% moisture content [29]. The natural bitumen is black in colour, specific gravity of 1.1$1.2 \mathrm{~g} / \mathrm{ml}$, softening point of $119^{\circ} \mathrm{C}$ and penetration of $0-2 \mathrm{~mm}$ [29]. The natural bitumen, however, requires modification to improve its penetration properties. Asphalt that was produced from acid tar meet the requirements of the Russian standards for bitumen grade 60/90 paving asphalt with respect to penetration, softening point, breaking point, flash point and adhesion to marbles but has low ductility of $3.9 \mathrm{~cm}$ at $25^{\circ} \mathrm{C}$ instead of 61 [30]. The adhesive properties of the bitumen are improved when mixed with polymers [31]. Copolymer of divinyl with styrene, atactic polypropylene, and co-polymer of ethylene with vinyl acetate, polychloroprene, polyisobutylene and natural rubber are polymers that are preferable for bitumen modification. From analysing the results by [31 and [29] natural bitumen can be mixed with asphalt to complement each other. In another research by [32] mixed asphalt with natural rubber to improve the viscosity. More viscose asphalt was found to have high softening point and this reduces the deformation, bleeding and increased pavement stability at high temperatures [32]

\section{Energy utilization of acid tars}

Table II gives the energy values of acid tars obtained from various tar lagoons. The variation in the energy content reported in the Table 2 is actually a function of the acid tar composition. The energy content depends mainly on the combustible carbon content. The energy values indicate that acid tars can be used as a source of fuel.

Table II: Energy values of acid tars

\begin{tabular}{|c|c|c|c|}
\hline Researcher & Place & Composition & Energy value \\
\hline [23] & $\begin{array}{l}\text { Mendeleev Yaroslavl } \\
\text { Refinery (Russia }\end{array}$ & $\begin{array}{llr}79 \% \text { Organics, } & 3 \% & \text { water, } \\
11,5 \% \mathrm{H}_{2} \mathrm{SO}_{4}, 5 \% & \text { Sulphur, } 6.5 \% \\
\text { ash content } & \end{array}$ & $33.5 \mathrm{MJ} / \mathrm{Kg}$ \\
\hline [33] & $\begin{array}{l}\text { Sydney Tar ponds. } \\
\text { (Nova Scotia Canada }\end{array}$ & $\begin{array}{l}51 \% \text { Moisture , 20.62\% ash, } 18.14 \% \\
\text { C, } 7.37 \% \mathrm{H}, 0.55 \% \mathrm{~N}, 1.12 \% \mathrm{~S}\end{array}$ & $9.47 \mathrm{MJ} / \mathrm{kg}$ \\
\hline [34] & Avonmouth England & $\begin{array}{l}34.90 \% \mathrm{C}, \quad 5.50 \% \mathrm{H}, \quad 6.35 \% \quad \mathrm{O} \\
, 0.30 \% \mathrm{~N}, \quad 2.12 \% \mathrm{~S}, 9 \% \text { Moisture, } \\
4.03 \% \text { Ash, } \\
25 \text { to } 50 \% \text { w/w Lead in ash, } \\
5000 \mathrm{Cp} \text { Viscosity and } 1.3 \text { Specific } \\
\text { gravity }\end{array}$ & $18.648 \mathrm{~kJ} / \mathrm{kg}$ \\
\hline
\end{tabular}

[35] Patented a process for the manufacture of boiler fuel from solid and high viscosity acid tars mixed with a straight run petroleum fraction. The resultant boiler fuel yield was found to be $92-97.4 \mathrm{wt} \%$. In another research, [27] showed that high yields of light petroleum products could be obtained from the thermal cracking of the organic components of the acid tars. The designed process by [27] yielded gaseous hydrocarbons (primarily, $\mathrm{C}_{1}-\mathrm{C}_{4}$ ) as well as liquid hydrocarbons that corresponded with the boiler or furnace fuel by composition. An enriched organic matter solid fuel was derived from acid tars using an organic admixture [36] and [37]. The admixture was pulverized and simultaneously heated to $200-300^{\circ} \mathrm{C}$, it was observed that the organic matter of the acid tar when heated to $200-300^{\circ} \mathrm{C}$ behaves as a reducing medium for sulphuric acid. Apart from processing the acid tars into a suitable fuel, some researchers tried to use the raw acid tar as a basic fuel. [23] Investigated the possibility of utilising the bottom layer of the acid tars which had been ponded for over a century at D.I Mendeleev Yaroslavl's oil refinery. The ponded acid tar had separated into three layers and the potential energy from the bottom layer was estimated at $16.76 * 10^{9} \mathrm{GJ}$ [23]. Their attempt to utilize the bottom layer as a basic fuel for the manufacturing energy carriers in ordinary boilers was a challenge due to the relatively high ash content of about $6.5 \%$, and the viscosities which did not allow burning in traditional boilers with fuel nozzles. However, with improved combustion technologies such as the circulating fluidised bed, combustion of the acid tars was found to be feasible. The technology proved to be effective in burning fuels with high moisture content and sulphur content without using expensive systems for scrubbing Nitrogen and Sulphur oxides from gases [38]. [39] Noted that the development of such fluidised bed technology on poor quality fuels 
was demonstrated way back in the 1960s. [40] attempted co-combustion of acid tars with coal in a bubbling fluidised bed combustor with a total heat input of about $2 \mathrm{MW}_{\mathrm{th}}$, with the share of the acid tar being about a half. A surprising result of $99 \%$ combustion efficiency was attained. The use of a fluidised bed combustor for burning acid tar, however, required that limestone be added to the bed material in order to provide some degree of sulphur capture [40]. By applying the limestone to the bed material, around $417 \mathrm{ppm}$ as opposed to $600 \mathrm{ppm} \mathrm{SO}_{2}$ emission limit as stipulated by the Commission of the European Communities was achieved using this method [40]. It can, therefore, be concluded from such an experience that the burning of viscous and sulphur containing wastes such as the acid tars can be demonstrated with a minimum effect on the environment. [41] Noted that the incineration of acid tars in fluidised bed technologies as a fuel substitute have not been well investigated.

\section{Ion exchangers and carbon adsorbents}

[42] Extensively studied the utilisation of acid tars in the synthesis of new reactive feed stocks for the manufacture of cationic exchangers. The feedstock for the manufacture of cationic exchangers was obtained from the redox reaction of oily acid tars and asphaltenes from naphtha deasphalting. Mixing acid tars from the treatment of transformer and automotive oils and naphtha deasphalting asphaltite produced a secondary petroleum residue with a group composition constituting $18.3 \%$ oils, $16.1 \%$ resins, and $65.6 \%$ asphaltenes. Sulphurisation with $20 \%$ oleum, produced a powdered sulpho cation exchanger with the following properties: static exchange capacity (SEC), $3.8 \mathrm{meq} / \mathrm{g}$; dynamic volume capacity (with $0.0035 \mathrm{~N}$ calcium chloride solution at unit load of 10 litres /litre.h), $489 \mathrm{meq} / \mathrm{g}$; bulk mass of air dried product, $0.59 \mathrm{~g} / \mathrm{ml}$; moisture content, $23.4 \%$; swelling in water, $39.2 \%$; and mechanical strength, 92\% [42].

Analysis of sulphurisation kinetics data showed very high reactivity of resins and asphaltenes from the acid tars and asphaltite. With respect to the properties the powdered cation exchanger made from petroleum resins and asphaltenes, [42] proposed their use in preliminary water treatment with metal gauze asbestos gravity filters at nuclear power plants.

In a technological process described by [42], acid tars can be utilised in the synthesis of polycondensates used as basic stocks for adsorbents. The resins and asphaltenes in acid tars can be used as additional source of feedstock, while the spent sulphuric acid can be used as a catalyst which solves the environmental problems of oil refineries. A mixture of cracking residues, furfural and acid tars in the ratio 33:25:22(wt) was used to fabricate the copolycondensate (furan -formolite). The stock for the adsorbents consisted of coal dust, furan -formolite, and wood tar in the ratio 39:39:22(wt). The adsorbents obtained were characterised by a high C.H ratio and molecular size pores. The sorption studies showed that they sorb gases methane, carbon dioxide and xenon to a much higher degree than industrial adsorbents. The adsorption, separating and selective properties of the cracking residue adsorbents were superior to industrial adsorbents for approximately the same pore size. The adsorbents obtained can be used for the treatment of difficulty sorbed and polar gases

\section{Conclusion}

A review of studies on acid tars has revealed that the environmental impacts of acid tars have not been fully explored and the constituents of the acid tar obtained by the various researchers differed. No resemblance in terms of the composition by weight can be drawn from these studies; however, the basic characteristics of acid tars remain similar despite the process by which the acid tar was derived. Analysis of acid tar requires pretreatment and the use of gas chromatography equipped with mass spectrometer detector is common. Various methods for the processing of acid tar into utilisable product have been tried in an attempt to reduce the long standing environmental problems associated with the disposal of acid tar in lagoons. Some of the utilisation processes which were reviewed included among others the conversion of acid tar to asphaltenes, production of pavement binders, energy utilisation, acid tar co-processing, membrane technology, ion exchangers and carbon adsorbents technique. These techniques, however, have not been conclusively investigated owing to the complexity of the acid tar. Accordingly, the deep-seated need for environmental sustainability still remains. Therefore, the problems experienced with the land fill disposal of highly corrosive acid tar wastes mean that an effective treatment method and utilisation techniques is needed for existing acid tar lagoons and the quantities that are still being generated by both crude petroleum and coal carbonisation processes world-wide.

\section{References}

[1]. Catney. P, Lawson. N, Palaseanu-Lvejoy. M, Shaw. S, Smith. C, Stafford. T, Tabot. S and Xuhao. (2005). Acid tar lagoons: risks and sustainable remediation in an urban context, paper presented to the SUBR: IM Conference March 2005.

[2]. Zilic-Fiser. S and Dvorsak. S. (2010) the model of an effective public communication in remediation of acid tar dump: case of Pesniski dvor.

[3]. Frolov. A. F, Aminov. A. N and Timrot. S. D (1981) Composition and properties of acid tar and asphalt produced from acid tar. Plenum publishers.

[4]. Burtanaya. I. A, Gachechiladze. O.O, Mitin. A. V, Prokhorov. S. A, Ruzhinskaya. L. I and Shafarenko. N. V (2007) Membrane technology for processing of acid tars, Chemistry and Technology of Fuels and Oils, 43: 521-523.

www.iosrjournals.org $20 \mid$ Page


[5]. Leonard. S. A, Stegemann. J. A and Roy. A. (2010 a), Characterization of acid tars, Hazardous material, 175: $383-392$

[6]. Khopkar. S. M (2008) Basic concepts of analytical chemistry, New age international Publishers. New Delhi: pp. 183-190.

[7]. Chojnacki. A, Chojnacka. K and Gorecki. H (2005) Utilization of spent petrochemical sulphuric acid in the production of wet process phosphoric acid, Journal of chemical technology and biotechnology, 80:1331-1338.

[8]. Kempe. C, Bellmann. C, Meyer. D and Windrich. F (2005) GC-IR based two dimensional structural group analysis of petroleum products, Anal bioanal chem. 382:186-191.

[9]. Ku. C. S and Mun. S. P (2006) Characterization of pyrolysis tar derived from lignocellulosic biomass, Industrial chemistry, 12: 853861

[10]. Semenova. S. A and Patrakov. Yu. F (2007) Effect of ozonation on the composition of crude coal-tar benzene, Russian journal of applied chemistry, 80: 846-850.

[11]. Hu. L, Zhou. Y, Zhang. M and Liu. R (2012). Characterization and properties of a lignosulfonate based phenolic foam, Bioresources, 7: 554-564

[12]. Rincon. J, Canizares. P and Garcia. M. T (2005) Waste oil recycling using mixtures of polar solvents, Industrial Engineering chemistry resources, $44:$ 7854-7859.

[13]. Semenova. S. A, Gavrilyuk. O. M, Zaostrovskii. A. N, Fedorova. N. I and Ismagilov. Z. R (2012) Modification of coal tar in low temperature oxygen plasma, Coke and chemistry, 55: 277-281.

[14]. LeThanh. H and Lendl B (2000) sequential injection Fourier transform infrared spectroscopy for simultaneous determination of organic acids and sugars in soft drinks employing automated solid phase extraction.Analytica chimica acta 422: 63-69

[15]. Jiang. J, Wang. Q, Wang. Y, Tong. W and Xiao. B. (2007). GC/MS analysis of coal tar composition produced from coal pyrolysis. Chemical society Ethiopia.21 (2): 229-240.

[16]. Kolmakov. G. A, Zanozina. V. F, Khmeleva. M. V, Okhlopkov. A. S, Grishin. D. F and Zorin. A. D (2006). Group analysis of acid tars. Petroleum chemistry, 46(1): 16-21.

[17]. Odebunmi. E. O and Adeniyi. S. A (2007) Infrared and ultra violet spectro-photometric analysis of chromatographic fractions of crude oils and petroleum products, Chemical society of Ethiopia, 21: 135-140.

[18]. Frolov. A. F, Titova. T. S, Karpova. I. V and Denisova. T. L. (1986) Composition of acid tars from sulphuric acid treatment of petroleum oils. Plenum publishers.

[19]. Nichol, D., (2000). Geo-engineering problems at Hoole Bank acid tar lagoon, Cheshire, UK. Land Contamination \& Reclamation, 8: $167-173$.

[20]. Aminov. A. N and Karpova. I. V (1989) Production of binders from acid pond tar, Plenum Publishing Corporation.

[21]. Yablokov. V. A, Kolmakov. G. A, Mitrofanova. S. V, Zanozina. V. F, Karataev. E. N, Zorin. A. D and Grishin. D. F. (2010). Kinetics of the thermal decomposition of acid tar. Petroleum chemistry. 50 (3): 237-241.

[22]. Nancarrow. D. J, Slade. N. J and Steeds. J. E (2001) Land contamination: Technical guidance on special sites: Acid tar lagoons, Environment agency UK.

[23]. Tumanovskii. A. G, Kosobokova. E. M and Ryabov. G. A. (2004). Production of energy carriers as a method of utilizing the bottom layer of acid tar. Chemistry and technology of fuels and oils, 40 (6): 351-357.

[24]. Chechulin. V. L (2008) Explaining the mechanism of electrochemical processing of some organic wastes, Chemistry and Technology of Fuels and Oils, $44: 71-72$

[25]. Druzina. B and Perc. A. (2010). Remediation of acid tar lagoon, Proceeding of the Annual International Conference on Soils, Sediments, Water and Energy, 15: 195-209.

[26]. Kolmakov. G. A, Zanozina. V. F, Karataev. E. N, Grishin. D. F and Zorin. A. D (2006 $)$. Thermal cracking of acid tars to asphalts as a process for utilization of refinery wastes. Petroleum chemistry 46 (6): 384-388

[27]. Zorin. A. D, Karataev. E. N, Zanozina. V. F, Knyazev. A. V and Zhebryakov. E. V (2012) Thin-film cracking of acid tars, Petroleum chemistry, 52: 245-252.

[28]. Vasudevan. R, Nigam. S. K, Velkennedy. R, Ramalinga. CS. A and Sundarakannan. B (2007). Utilization of waste polymers for flexible pavement and easy disposal of waste polymers, Proceedings of the international conference of sustainable solid waste management, Chennai, India, pp 105-111

[29]. Mortazavi. S. B, Rasoulzadeh. Y, Yousefi. A. A and Khavanin. A. (2010) Properties of modified bitumen obtained from vacuum bottom by adding recycled waste polymers and natural bitumen. Iranian polymer journal, 19 (3): 197-205

[30]. Frolov. A. F, Aminov. A. N, Veselov. A. N, Lysenko. B. G and Timrot. S. D (1980) Production of paving asphalt from acid tar. Plenum publishers.

[31]. Voitovich. V. A (2010) Adhesives and sealants based on bitumen, Polymer Sciences (series D.Glues and sealing materials) 3: 238240.

[32]. Tuntiworawit. N, Lavansiri. D and Phromsorn. C. (2005). The modification of asphalt with natural rubber latex. Proceedings of eastern Asia Society for transportation studies, 5: 679- 694.

[33]. Jia. L, Anthony. EJ and Turnbell, R. (2005) Treatment of Tar Pond Sludge in a circulating fluidized bed combustor .Remediation Journal. 15 (2) : 63-73

[34]. Commission of the European Community ,2006,Case No 74 -43-6

[35]. Lyaklevich G.D. and Rudkovskii A.D., (1979), USSR Inventor's Certificate No. 654 666, Byull Izobret, No. 12

[36]. Antonishin V.I. And Fast A.N., USSR Inventor's Certificate No. 454 244, Byull Izobret, No. 7 (1974)

[37]. Kondakov D.I., Khuramshin T.Z., Sapunov G.Z,(1976) USSR Inventor's Certificate No. 515 773, Byull Izobret, No. 20

[38]. Koornneef J., Junginger M., and Faaij A., (2007) Development of Fluidised Bed Combustion- an Overview of trends, performance and cost; ELSEVIER, Progress in Energy and Combustion Science, 33:19-55.

[39]. Yue, G.X. Yang. H. R, Lu. JF, and Zhang, H ,2009.Latest Development of CFD Boilers in China: Proceedings of the International Conference on Fluidized Bed Combustion

[40]. Kerr and Probert S.D. (1990), Fluidized bed incineration of acid tar waste, Applied Energy 35: 189-243.

[41]. Leonard. S. A and Stegemann. J. A (2010). Stabilization/solidification of acid tars. Environmental science and health part A, 45: 978-991.

[42]. Pokonova. (2003), Thermal Cracking Resids as a Base for Carbon Adsorbents and Ion Exchangers. Chemistry and Technology of Fuels and Oils, 39. (5): 278-289. 